\title{
Barthes e a Dimensão Amorosa da Escritura*
}

\author{
Dilma Castelo Branco Diniz ${ }^{1}$
}

RESUMO: Uma leitura da retórica na $A u l a$ de Roland Barthes procurando captar, no texto, a estrutura metonímica característica do desejo.

No prefácio de seus Essais Critiques, ${ }^{2}$ Roland Barthes fala da retórica como uma técnica literária que consiste na arte de variar o banal pelo recurso às substituições e aos deslocamentos de sentido. E explica melhor o seu pensamento com o exemplo que se segue. Um seu amigo acaba de perder uma pessoa muito querida e ele se dispõe a escrever-lhe uma carta. Começa a escrever, mas suas palavras não o satisfazem. Ele quer comunicar ao amigo sua compaixão e sua mensagem poderia muito bem se resumir em duas palavras: "Meus sentimentos". Entretanto, o fim mesmo da comunicação se oporia a isto, porque uma tal mensagem soaria fria, e conseqüentemente invertida, já que o que ele quer comunicar é justamente o calor de sua compaixão. E conclui que, para tornar sua mensagem exata, é preciso variá-la e essa variação deve ser original, assim como inventada.

Compara a literatura com o processo de escrita dessa carta de pêsames: toda escrita se transforma em obra de arte, quando consegue variar, sob certas condições, uma mensagem primeira. Estas

* Recebido para publicação em abril de 1988. Este artigo foi originalmente apresentado como trabalho final do curso «Metodologia da Crítica Literária I» (Mestrado em Letras - $1^{\text {o }}$ semestre de 1988 - UFMG) ministrado pela Prof Doutora Eneida Maria de Souza.

1. Aluna do Curso de Mestrado da Faculdade de Letras da UFMG.

2. BARTHES, 1964. p. 11-2. 
condições constituem o próprio ser da literatura, aquilo que os formalistas russos chamaram de "literaturnost" ou "literariedade".3 Esta originalidade é o fundamento mesmo da literatura, porque é somente se submetendo à sua lei, que se tem a possibilidade de comunicar com exatidão o pensamento. Escrevendo simplesmente "Meus sentimentos", a compaixão de Barthes transformar-se-ia em indiferença.

Torna-se pois importantíssimo, tanto na literatura quanto na comunicação particular, saber escolher bem as palavras, a melhor conotação, para deformar o menos possível não propriamente o que se quer dizer, mas, sobretudo, o que se quer fazer compreender.

Assim, a originalidade é uma necessidade para ser acolhido (e não só compreendido) por quem nos lê ou nos ouve. E como a comunicação é afetiva, o luxo nos detalhes é imprescindível e a banalidade se transforma numa grande ameaça. Existe ainda o perigo contrário: a linguagem pode tornar-se original demais e escapar do limite da compreensão. Aparece, então, uma zona vigiada e vital - a retórica - cuja dupla função é evitar que a literatura se transforme num signo da banalidade (se ela for por demais direta) ou num signo da originalidade (se for demasiadamente indireta).

Barthes ainda assinala que as fronteiras da retórica podem se alargar ou diminuir, do gongorismo à escrita "branca", mas é certo que a retórica está ligada não só a toda literatura, mas ainda a toda comunicação, desde que ela queira fazer compreender ao outro que nós o reconhecemos: "la rhétorique est la dimension amoureuse de l'écriture".4 E continua dizendo que o desejo é o significado primeiro da obra literária: "écrire est un mode de l'Eros". 4

Ora, Jacques Lacan propõe o célebre axioma: O Inconsciente é estruturado como uma linguagem",, 5 e toma a estrutura metafórica como ponto de referência para descrever o sintoma e "a estrutura metonímica para caracterizar a estrutura do desejo". ${ }^{6}$

Convém lembrar aqui que o linguísta Roman Jakobson propôs, como diretrizes semânticas, dois eixos fundamentais da produção do significado: o processo metonímico e o processo metafórico. O desen-

3. EIKHENBAUM, 1973. p. 8.

4. EIKHEENBAUM, 1973. p. 14.

5. BELLEMIN, 1983, p. 28.

6. VLALLEJO \& MAGALHÃES, 1981. p. 25. 
volvimento de um discurso ocorre segundo estas duas linhas semânticas diferentes: um tema pode levar a outro ou pela similaridade (ligada à metáfora) ou pela contigüidade (ligada à metonímia) .

A competição entre esses dois procedimentos metonímico e metafórico aparece em todo processo simbólico, seja ele subjetivo ou social. Freud, em seus estudos sobre os sonhos, estabelece a ligação entre condensação e metáfora e deslocamento e metonímia. Vemos, portanto, que se pode assim aproximar a retórica da verbalização enviezada do desejo.

Tentaremos fazer uma leitura da $A u l a^{7}$ de Barthes, procurando captar, no texto, a estrutura metonímica que caracteriza o desejo.

Em 17 de janeiro de 1977, Roland Barthes pronunciou sua aula inaugural no Collège de France, como ocupante da cátedra de Semiologia Literária. A Aula é precisamente esse texsto que, numa forma nitidamente retórica, começa com o elogio da dignidade que lhe foi conferida. Os professores do Collège de France, como talvez se saiba, limitam-se a falar: não têm a obrigação de julgar, aprovar ou dar diplomas aos alunos. Barthes fala, então, de sua alegria por entrar num lugar "fora do poder".

Essa expressão, "lugar fora do poder", é metonímica: o poder, significando "um certo poder", o poder que regula os estabelecimentos de ensino, é visto não como uma verdade particular, mas como uma verdade absoluta: "todo e qualquer poder". A parte, assim, é tomada pelo todo. Existe neste procedimento retórico uma fascinação, resultado de um adormecimento da consciência crítica, necessariamente comparativa, e com isso o orador seduz os ouvintes.

Mas, continuando sua alocução, Barthes volta atrás, quando diz que o poder está escondido em todo discurso, mesmo se este parte de um lugar fora do poder. Segue-se uma preleção sobre o poder: é um objeto político, ideológico e plural como os demônios. Nesta comparação entra toda uma conotação negativa ligada à demonologia cristã, já que ele cita a palavra evangélica "Meu nome é Legião" . ${ }^{8}$ O poder é plural no espaço social e perpétuo no tempo histórico; nunca perece: expulso de um lugar reaparece em outro. Isto, porque o poder vive ligado ao homem, inscrito que está em sua linguagem, mais precisamente em sua língua.

7. BARTHES, s.d. As citações são extraídas desta edição.

8. EVANGELHO... 1953. p. 1213. 
"A linguagem é uma legislação, a língua é seu código. Não vemos o poder que reside na língua porque esquecemos que toda língua é uma classificação e que toda classificação é opressiva: ordo quer dizer, ao mesmo tempo, repartição e cominação". (A. p. 12)

E dá exemplos da língua francesa que o obriga a se posicionar como sujeito numa enunciação, a escolher entre o masculino e o feminino, já que o neutro lhe é proibido, quando se dirige a uma outra pessoa, deve escolher entre o "tu" e o "vós", etc.

"Assim por sua própria estrutura, a língua implica uma relação fatal de alienação. Falar, e com mais razão discorrer, não é comunicar, como se repete com demasiada frequiência, é sujeitar: toda língua é uma reição generalizada". (A. p. 13)

E conclui com uma frase que provocou muita polêmica: "

"a língua como desempenho de toda linguagem não é nem reacionária, nem progressista; ela é simplesmente: fascista, pois o fascismo não é impedir de dizer, é obrigar a dizer." (A. p. 14)

A língua é portanto poder, porque me obriga a usar os signos, que só existem na medida em que são do conhecimento das pessoas que usam o mesmo código. Dessa forma em cada signo esconde-se um estereótipo. Entretanto, quando enuncio sou ao mesmo tempo "mestre" (já que posso escolher no repertório dos signos existentes na língua os que mais se ajustam ao meu pensamento) e "escravo" (pois sou obrigado a me sujeitar a este repertório). Na língua, servidão e poder se confundem. Só haveria então completa liberdade fora da língua, mas a língua é um lugar fechado: sair dela é impossível. Resta-nos burlar a língua, trapacear com ela e esse jogo, ao mesmo tempo salutar e libertador, chama-se literatura.

Do lugar fora do poder, Barthes passa para o discurso ali proferido, numa relação de contigüidade espacial. Do poder existente nesse discurso ele passa ao poder que se esconde em todo o tempo e lugar e que ninguém vê, porque está emboscado na língua - outra relação de contiguiidade, pois todo discurso utiliza uma língua. $\mathrm{E}$ da língua passa à literatura, que ele chama indiferentemente de escritura ou texto, sendo o texto o "próprio aflorar da língua" (p.17). Podemos perceber a série de desvios que, aos poucos, vai construindo o texto e nos levando junto, numa incursão 
ou excursão, como ele prefere dizer, criando um método que procura desprender ou ao menos aligeirar o poder existente na língua.

Em seguida, Barthes descreve as forças da liberdade que residem na literatura, passando do instrumento (a língua literária) à ação (as forças da literatura) em mais uma contiguiidade de sentidos. São destacadas três forças que ele coloca sob três conceitos gregos: Mathesis, Mimesis e Semiosis.

Explicitando a Mathesis, ele fala que a literatura assume muitos saberes, até os saberes possíveis, insuspeitos e irrealizáveis. Ela trabalha nos interstícios da ciência, às vezes adiantada às descobertas científicas, outras vezes atrasada. Na escritura, não só coexistem as áreas do conhecimento e da afetividade - o "saber" e o "sabor" - como há uma interação muito proveitosa entre elas: "E esse gosto das palavras que faz o saber profundo, fecundo". (A. p. 21) .

$\overline{\mathrm{E}}$ interessante notar o jogo estabelecido entre as palavras "saber" e "sabor", de mesma origem etimológica, denunciando, por um lado, um desvio semântico e, por outro, proporcionando prazer a quem fala e a quem ouve. Assim, Barthes une a teoria à prática. $\mathrm{E}$ por ser em parte um jogo é que a literatura é julgada muitas vezes como inútil, mas em compensação oferece sempre prazeres inefáveis: "a escritura faz do saber uma festa" (A. p.21).

A segunda força da escritura é a representação: a Mimesis. Desde os seus primórdios, a literatura trabalha para representar o real. Mas o real é irrepresentável, seja porque é o "impossível", como o define Lacan (o real escapa à simbolização e se situa à margem da linguagem) seja porque, em termos topológicos, não se pode ajustar uma ordem pluridimensional (o real) a uma ordem unidimensional (a linguagem).

Surge assim um outro jogo de palavras que se assemelha a um paradoxo:

"a literatura é categoricamente realista, na medida em que ela sempre tem o real por objeto do desejo; e direi agora sem me contradizer, porque emprego a palavra em sua acepção familiar, que ela é também obstinadamente: irrealista; ela aceita sensato o desejo do impossível." AA. p. 23)

Por ser impossível a representação do real, esta função torna-se utópica e daí segue-se uma referência à utopia, por um processo de transferência de sentido claramente metonímico. 
Aproximando a expressão de Mallarmé "mudar a língua" da expressão vizinha de Marx "mudar o mundo", utopia e História se unem numa nova visão profética - a escritura.

Mas o tema do poder é sempre recorrente no texto, e Barthes lembra que a utopia não preserva do poder: muitas vezes, o poder se apossa do gozo de escrever para manipulá-lo. A saída para o autor, então, só se dará pelo deslocamento ou pela teimosia, ou ainda os dois ao mesmo tempo. Teimar é resistir e sobreviver aos discursos tipificados que o rodeiam; e é porque o autor teima, que a escritura é levada a deslocar-se. Ora, "teimar" e "deslocar-se" são métodos de jogo e jogar com os signos é a terceira força literária, sua força propriamente semiótica. Trata-se da Semiologia. E Barthes passa a falar da ciência, já que a semiologia é a ciência dos signos, para dizer que as ciências não são eternas e que a lingüística é uma ciência que atualmente se encontra em desconstrução e que é esta desconstrução mesma que ele chama de semiologia.

Ele mesmo revela que passou sub-repticiamente da língua ao discurso para voltar, sem avisar, à língua, considerando os dois como um mesmo objeto. A distinção entre língua e discurso não aparece mais atualmente, a não ser como operação passageira, algo a "abjurar":

"a língua aflui no discurso e o discurso reflui na língua, eles persistem um sob o outro, como brincadeira de mão" (A. p. 32),

Mantendo essa distinção, a lingüística parece que está trabalhando sobre um enorme engano.

Surge em seguida a definição de Semiologia, uma definição que ele confessa ser bem pessoal, mas que reflete a sua aventura, um certo trabalho individual que pretende prosseguir no Collège de France.

"A semiologia seria aquele trabalho, que recolhe o impuro da língua, o refugo da linguística, a corrupção imediata da mensagem: nada menos do que os desejos, os temores, as caras, as intimidações, as aproximações, as ternuras, os protestos, as desculpas, as agressões, as músicas de que é feita a língua ativa" (A. p. 32) .

Afirma que sua semiologia nasceu de um movimento passional: uma ciência dos signos pareceu-lhe poder ativar a crítica social, 
tratando de compreender e descrever a formação dos estereótipos dentro de uma sociedade. O objeto de sua primeira semiologia foi, por conseguinte, a "língua trabalhada pelo poder" (p. 33). Depois disto, a semiologia se deslocou, conservando todavia sempre o mesmo objeto político, pois não existe outro, até voltar ao Texto, "o próprio índice do despoder", onde Semiologia e literatura se unem corrigindo uma a outra.

Barthes fala da semiologia usando, mais uma vez, termos gregos. Ela não seria uma "semiófisis, uma naturalidade inerte do signo", nem uma "semioclastia, uma destruição do signo", mas seria antes uma "semiotropia", voltada para o signo:

"este (o signo) a cativa e ela o recebe, o trata e, se preciso for, o imita, como um espetáculo imaginário." ( $A$. p. 40)

Esse gozo do signo imaginário é hoje concebível, graças a mudanças sociais e culturais que desmistificaram "o grande escritor francês" e dessacralizaram a literatura, permitindo um maior contacto das forças literárias com o povo. E afirma que este é um "momento histórico do maior gozo" (A. p. 42) .

A passagem do "gozo do signo imaginário" ao contexto histórico-cultural que permitiu sua expansão revela uma co-dependência a uma totalidade material dentro do plano referencial. Se na metáfora o termo intermediário é englobado, na metonímia é sempre englobante. O termo intermediário, nesse caso, é a totalidade espaçotemporal compreendida pela vida e cultura francesas da segunda metade do século $\mathrm{XX}$, principalmente depois da revolução de maio de 68 que, com sua carga libertária, renovou os valores sociais.

Desse contexto histórico em que se manifestou a crise do ensino francês, Barthes passa ao ensino no Collège de France onde só importa a "fidelidade de seus ouvintes". Discute então a questão do método, que deve "manter" o discurso sem o impor, frisando a forma, pois :

"o que pode ser opressivo num ensino não é finalmente o saber ou a cultura que ele veicula, são as formas discursivas através das quais é proposto" (A. p. 43).

Insiste na afetividade da comunicação e propõe um ensino fantasmático. Ora, o fantasma tem um caráter misto, pois participa ao mesmo tempo do inconsciente e do sistema Pré-Consciente-Consciente. 
Um ensino fantasmático envolveria, portanto, todos os aspectos da personalidade humana, seria um ensino por assim dizer completo.

E Barthes termina sua alocução dizendo que está entrando numa vida nova (numa clara referência à Vita Nuova de Dante) marcada por um lugar novo, nova hospitalidade e que quer agora deixar-se levar pelo esquecimento. $\mathrm{E}$ essa experiência de desaprender tem um nome

"Sapientia: nenhum poder, um pouco de saber, um pouco de sabedoria, e o máximo de sabor possível" ( $A$. p. 47).

Lacan define a metonímia com a expressão "palavra à palavra", 9 revelando uma relação de continuidade. E é esta continuidade que está presente em todo o texto da aula, marcando a enunciação. A enunciação que, mostrando o lugar e a energia do sujeito e mesmo sua falta (que não é uma ausência), visa o real mesmo da linguagem. E "a literatura tem sempre o real por objeto do desejo" (A. p. 23) .

Um grande descobrimento da Psicanálise foi perceber que em todo processo de enunciação há um discurso que vai além, e em direção diferente, ao conteúdo do enunciado. Leyla Perrone-Moisés assinalou com muita propriedade que o "sujeito dessa enunciação permanece incerto." ( $A$. p. 57) Se o lado clássico de Barthes é muito capaz de proferir tal discurso a sério, o seu lado anarquista é bem susceptível de sorrir sob a máscara... Ela continua dizendo que

"A ironia é uma forma clássica de distanciamento (ele próprio o disse, mais de uma vez); ela supõe uma hierarquia, um olhar lançado de cima. Daí a pergunta: a ironia não é uma forma discursiva de poder?" (A. p. 57)

Porém o que Barthes preconiza em toda essa Aula é um combate ao estereótipo, para evitar que o discurso se solidifique nas ilusões da naturalidade e nas tentações do autoritarismo. Expõe um método de ensino que tem por objeto a própria linguagem que luta para baldar, desprender ou pelo menos aligeirar o poder do discurso. Sugere a fragmentação e a digressão e ousa um ensino fantasmático, recusando-se a ocupar o lugar do Pai. E Leyla conclui que a ironia maior dessa Aula talvez resida no fato de que, sob o título cheio

9. VALLEJO \& MAGALHĀES, 1981. p. 94. 
de conotações hierárquicas, institucionais e moralistas - Leçon ela desmonte, em seu próprio desenvolvimento, essas conotações.

Entretanto, existe no texto uma ironia quase imperceptível, que funciona como um mecanismo retórico de sedução, um meio pelo qual a compreensão, ficando garantida, asseguraria por sua vez a inclusão ou a satisfação do leitor. Essa ironia nasce de um excesso de modéstia, polidez e elegância, sublinhando o antiquado. E a ironia é tanto mais eficaz quanto mais sutil, e no caso da $A u l a$ ela está quase ausente.

Pudemos verificar que a tônica dessa $A u l a$ de Barthes está centrada na metonímia. E Lacan toma a metonímia como o ponto de referência para caracterizar a estrutura do desejo. Na metonímia há um deslocamento, na ordem sintagmática, que permite a elisão do significante que desaparece, para surgir no significante com que está em relação de contiguiidade. O deslocamento permite a elisão pela qual o significante instala a falta de ser na relação com o objeto e, dessa forma, Lacan introduz toda a problemática do desejo.

Em Lacan: operadores de leitura ${ }^{10}$ podemos ler:

"A metonímia, um significante que desaparece maciçamente, parece ser o recurso mais apto para despistar a censura, na medida em que o significante desaparecido traça, em negativo, o lugar em que se circunscreve a censura social".

A metonímia vista assim pode ser compreendida como uma arte de enganar a censura e está intimamente ligada à noção de descentramento do sujeito. Ao mesmo tempo em que a falta desliza, algo insiste como verdadeiro enquanto desejo e se articula como tal. E segundo a teoria lacaniana, "o desejo do homem é o desejo do Outro". ${ }^{11}$ Lacan escreve:

"O desejo do homem encontra seu sentido no desejo do outro, não tanto porque o outro detenha as chaves do objeto desejado, mas porque seu primeiro objeto é ser reconhecido pelo outro". ${ }^{12}$

Mas quem é esse outro que ademais é esse Outro? Lacan responde resoluto: "O lugar de deslocamento do discurso".12 Tra-

10. VALLEJO \& MAGALHÃES, 1981. p. 94.

11. FAGES, 1975. p. 43.

12. Tbidem. p. 45. 
ta-se da dialética sem fim do desejo: o desejo de ser reconhecido pelo outro passa obrigatoriamente pela linguagem.

Pois bem, aprendemos com Barthes no prefácio de Essais Critiques que quem quer escrever com exatidão deve-se colocar nas fronteiras da linguagem, pois só assim é que se escreve verdadeiramente para os outros, já que nenhuma mensagem direta pode comunicar o sentimento. $O$ escritor deve escutar sua própria palavra que se constitui assim como uma palavra recebida, embora seja palavra criada, que é a palavra mesma da literatura.

Nesta $A u l a$, pode-se perceber toda a sedução que emana do texto e que deriva de sua forma retórica: da dimensão amorosa de sua escritura. E podemos assinalar que

"L'écriture est en effet, à tous les niveaux, la parole de l'autre et l'on peut voir dans ce renversement paradoxal le véritable "don" de l'écrivain." 13

RESUME: Une lecture de la rhétorique dans la Leçon de Roland Barthes tentant d'y saisir la structure métonymique qui caractérise le désir.

\section{REFERENCIAS BIBLIOGRĀFICAS}

BARTHES, Roland. Aula. Trad. Leyla Perrone-Moisés. São Paulo, Cultrix, s.d. BARTHES, Roland. Essais critiques. Paris, Ed. du Seuil, 1964.

BELLEMIN NOEL, J, Psicanálise e literatura. Trad. Alvaro Sorencini e Sandra Nitrini. São Paulo, Cultrix, 1983.

EIKHFENBAUM, B. A teoria do método formal. In: TOLEDO,D. de Oliveira, org. Teoria da literatura, formalistas russos. Porto Alegre, Globo, 1973.

EVANGELHO de São Marcos cap. V, vers. 9. In: BÍBLIA Sagrada, 6. ed. São Paulo, Edições Paulinas, 1953.

FAGES, Jean-Baptiste. Para ocmpreender Lacan. 2. ed. Trad. M. D. Magno e Georges Lamarière. Rio de Janeiro, Edd. Rio, 1975.

VALLEJO, A. \& MAGALHÃES', L. Lacan! operadores de leitura. São Paulo, Perspectiva, 1981.

13. BARTHES, 1964. p. 13. 